\title{
A sampling of Canadian practices in managing nonvariceal upper gastrointestinal bleeding before recent guideline publication: Is there room for improvement?
}

\author{
Karen Bensoussan MD MSc, Carlo A Fallone MD FRCPC, Alan N Barkun MD FRCPC MSc(Epid),
} Myriam Martel BSc, and the RUGBE Investigators*

K Bensoussan, CA Fallone, AN Barkun, M Martel, and the RUGBE Investigators. A sampling of Canadian practices in managing nonvariceal upper gastrointestinal bleeding before recent guideline publication: Is there room for improvement? Can J Gastroenterol 2005;19(8):487-495.

BACKGROUND: There are few recent published consensus guidelines regarding nonvariceal upper gastrointestinal bleeding. In 2003, the Canadian Association of Gastroenterology sponsored a set of 20 recommendations.

AIM: To compare current Canadian clinical practice patterns with these most recent guidelines.

METHODS: Data obtained from the Canadian Registry of patients with Upper Gastrointestinal Bleeding and Endoscopy (RUGBE), complemented by a questionnaire sent out to the 18 participating RUGBE sites, were used to compare present practice with all 20 guidelines.

RESULTS: Only three RUGBE sites had an explicit written protocol for nonvariceal upper gastrointestinal bleeding, and only $40 \%$ of the sites had support staff available after hours. The Blatchford prognostic scale was not used routinely, and only one site used the Rockall score for risk stratification. Most patients classified as low-risk according to the literature had endoscopy within $24 \mathrm{~h}$ and a median length of stay of two days compared with high-risk patients who underwent endoscopy approximately $4 \mathrm{~h}$ earlier, had a median length of stay of 4.3 days and displayed a higher mortality. Nineteen per cent of all patients had a routine second-look endoscopy. Proton pump inhibitors were frequently used in the acute setting. Thirteen per cent of all patients rebled and only $34 \%$ of these received a second endoscopy. One-half of all patients were tested for Helicobacter pylori while in hospital, mostly by histology, and one-third of those who tested positive received $H$ pylori eradication during their hospitalization.

CONCLUSION: Compared with recommendations put forward in the new guidelines, clinical practice before guideline publication was variable. The future level of guideline adherence and patient outcome data should be quantified and monitored as the guidelines are disseminated.

Key Words: Canadian; Consensus; Guideline; Nonvariceal Upper Gastrointestinal Bleeding; Practice; RUGBE

\section{Aperçu de la pratique canadienne en présence d'hémorragie digestive haute non variqueuse avant la publication de nouvelles directives : Y a-t-il place à l'amélioration?}

HISTORIQUE : Peu de directives consensuelles ont été publiées récemment au sujet du traitement de l'hémorragie digestive haute non variqueuse, mais en 2003, l'Association canadienne de gastroentérologie (ACG) a mis de l'avant une série de 20 recommandations.

BUT : Comparer la pratique clinique canadienne actuelle à celle des directives les plus récentes.

MÉTHODE : Des données tirées du projet RUGBE (pour Registry of patients with Upper Gastrointestinal Bleeding and Endoscopy) et complétées par un questionnaire qui a été envoyé à 18 sites participants ont été utilisées pour comparer l'application des 20 directives dans la pratique actuelle.

RÉSULTATS : Seulement trois sites participants au RUGBE étaient dotés d'un protocole documenté et précis pour le traitement de l'hémorragie digestive haute non variqueuse et $40 \%$ seulement des sites disposaient de personnel après les heures d'ouverture. L'échelle pronostique de Blatchford n'était pas utilisée d'emblée et seul un site se fiait à l'indice de Rockall pour la stratification du risque. La plupart des patients classés dans une catégorie à risque faible selon les critères énoncés dans la littérature subissaient leur endoscopie dans les 24 heures et la durée médiane de leur séjour était de deux jours, comparativement aux patients à haut risque qui subissaient leur endoscopie environ quatre heures plus tôt, étaient hospitalisés pendant une durée médiane de 4,3 jours et avaient un taux de mortalité plus élevé. Dix-neuf pour cent de tous les patients subissaient d'emblée une endoscopie de contrôle. Des inhibiteurs de la pompe à protons étaient fréquemment utilisés durant la phase aiguë. Treize pour cent de tous les patients ont saigné de nouveau et $34 \%$ d'entre eux ont subi une seconde endoscopie. La moitié de tous les patients ont subi un test de dépistage de Helicobacter pylori durant leur hospitalisation, la plupart par méthode histologique, et un tiers de ceux dont les résultats étaient positifs ont reçu un traitement d'éradication de $H$. pylori durant leur hospitalisation.

CONCLUSION : Si on la compare aux recommandations mises de l'avant dans les directives récentes, la pratique clinique s'est révélée inégale. Il faudra mesurer et vérifier la conformité aux recommandations et les résultats obtenus chez les patients lorsque de nouvelles directives seront émises.

disease (PUD) accounts for $50 \%$ to $70 \%$ of NVUGIB (3) and the mortality is $6 \%$ to $8 \%$ (1). The average cost per hospitalized patient with NVUGIB in the United States varies between US\$7,993 and US\$11,802 (4), and in Canada, between $\$ 2,696$ and $\$ 5,220$ (4).
$\mathrm{N}$ onvariceal upper gastrointestinal bleeding (NVUGIB) is a significant cause of morbidity and mortality. There are approximately 170 cases per 100,000 adults per year (1), which represents an annual economic burden of approximately US\$1 billion in the United States (2). Peptic ulcer

Division of Gastroenterology, McGill University Health Centre, Montreal, Quebec. *See appendix

Correspondence: Dr Carlo A Fallone, McGill University Health Centre - Royal Victoria Hospital, 687 Pine Avenue West, Room R2.28,

Montreal, Quebec H3A 1A1. Telephone 514-843-1616, fax 514-843-1421, e-mail carlo.fallone@mcgill.ca 


\section{TABLE 1}

Canadian Association of Gastroenterology 2003 consensus guidelines regarding nonvariceal upper gastrointestinal (GI) bleeding
1) Hospitals should develop institution-specific protocols for multidisciplinary management, which should include access to an endoscopist with training in endoscopic hemostasis
2) Support staff trained to assist in endoscopy should be available for urgent endoscopy
3) Immediate evaluation and appropriate resuscitation are critical to proper management
4) In selected patients, the placement of a nasogastric tube can be considered because the findings may have prognostic value
5.1) Clinical (nonendoscopic) stratification of patients into low- and high-risk categories for rebleeding and mortality is important for proper management. Available prognostic scales may be used to assist in decision-making

5.2) Early stratification of patients into low- and high-risk categories for rebleeding and mortality, based on clinical and endoscopic criteria, is important for proper management. Available prognostic scales may be used to assist in decision-making

6) Early endoscopy (within the first $24 \mathrm{~h}$ ) with risk classification by clinical and endoscopic criteria allows for safe and prompt discharge of patients classified as low risk; improves patient outcomes for patients classified as high risk and reduces resource utilization for patients classified as either low or high risk

7) a) A finding of low-risk endoscopic stigmata (a clean-based ulcer or a nonprotuberant pigmented dot in ulcer bed) is not an indication for endoscopic hemostatic therapy

b) A finding of a clot in an ulcer bed warrants targeted irrigation in an attempt at dislodgement, with appropriate treatment of the underlying lesion

c) A finding of high-risk endoscopic stigmata (active bleeding of a visible vessel in an ulcer bed) is an indication for immediate endoscopic hemostatic therapy

8) No single solution for endoscopic injection therapy is superior to another for hemostasis

9) No single method of endoscopic thermal coaptive therapy is superior to another

10) Monotherapy, with injection or thermal coagulation, is an effective endoscopic hemostatic technique for high-risk stigmata; however, the combination is superior to either treatment alone

11) The placement of clips is a promising endoscopic hemostatic therapy for high-risk stigmata

12) Routine second-look endoscopy is not recommended

13) In case of rebleeding, a second attempt at endoscopic therapy is generally recommended

14) Surgical consultation should be sought for patients who have failed endoscopic therapy

15) $\mathrm{H}_{2}$-receptor antagonists are not recommended in the management of patients with acute upper GI bleeding

16) Somatostatin and octreotide are not recommended in the routine management of patients with acute nonvariceal upper GI bleeding

17) An intravenous bolus followed by continuous-infusion proton pump inhibitor is effective in decreasing rebleeding in patients who have undergone successful endoscopic therapy

18) In patients awaiting endoscopy, empirical therapy with a high-dose proton pump inhibitor should be considered

19) Patients considered at low risk for rebleeding after endoscopy can be fed within $24 \mathrm{~h}$

20) Patients with upper GI bleeding should be tested for Helicobacter pylori and receive eradication therapy

Data from reference 5

The management of NVUGIB has evolved over the past 10 years; however, there have been very few published consensus guidelines regarding the management of NVUGIB (5). In 2003, a group of experts from many North American and international professional societies generated 20 consensus recommendations or guidelines for managing NVUGIB under the aegis of the Canadian Association of Gastroenterology (5) (Table 1). Guidelines seek and synthesize sound evidence, generate recommendations and try to influence what clinicians do with the hope that there will be less practice variation, lower costs and improved health outcomes (6). Some studies suggest that guidelines can have a positive impact on patient outcomes (6-9) but others have shown little effect (10).

The present study aimed to identify the current practice patterns of NVUGIB in Canada and compare these with the new guidelines to determine whether dissemination of these guidelines is required. The Canadian Registry of patients with Upper Gastrointestinal Bleeding and Endoscopy (RUGBE) (11) database was used. The RUGBE data were collected between 1999 and 2002 (11), just before the consensus meeting and guideline publication. To complement these data, questionnaires were also sent to the RUGBE institutions where appropriate.
Study design

\section{METHODS}

The 20 Canadian Association of Gastroenterology consensus statements for managing NVUGIB were individually assessed (Table 1). For each recommendation, it was determined whether the information in the RUGBE database was sufficient to assess the clinical practice patterns. The RUGBE database is a retrospective registry from 1869 randomly selected patients who were endoscoped for NVUGIB at 12 Canadian university-affiliated and six community institutions between 1999 and 2002 (11). The data collected included patient demographics, past medical history, vital signs on arrival to hospital, initial laboratory values, resuscitative efforts with intravenous (IV) fluids or blood transfusions, and endoscopic information in terms of diagnosis and endoscopic treatment. Helicobacter pylori status and medications used were also documented. Patient outcomes were tracked for 30 days after the initial event with regard to continuous bleeding, rebleeding, surgery and death.

For eight guidelines, the data from the RUGBE dataset were insufficient to assess the clinical practice patterns. To complement the database, a questionnaire was designed and circulated to the 18 sites that participated in the collection of the RUGBE database. From December 2003 to January 2004, this short questionnaire was sent out by e-mail and faxed to the respective sites. 
A follow-up e-mail message was sent out three weeks later to seven of the sites that had not yet responded to the questionnaire.

\section{Patient population}

For the purpose of the present analysis, and to get a more homogeneous group with regard to practice management, only patients who presented as outpatients in the RUGBE database were considered. Therefore, the study population included 1240 patients, because the remaining 629 patients in the RUGBE database included either patients already in hospital for other reasons when they started bleeding or patients transferred from other hospitals.

\section{Statistical analysis}

Descriptive data were generated using the SAS program (SAS Institute, USA) for all RUGBE variables. Data are presented as median and range depending on the spread of the data for continuous variables, and percentage with, where appropriate, 95\% CIs calculated using the normal approximation of the binomial distribution. The 95\% CIs were not calculated for the percentage results from the questionnaire responses due to the small sample size $(n=15)$ that limits their interpretation and clinical relevance. Therefore, only the 95\% CIs for the RUGBE database are presented.

\section{Planned subgroup analyses}

With regard to guidelines that required clinical and endoscopic risk stratification (eg, guideline 6), patients from the RUGBE database were determined to be at low or high risk based on criteria most commonly used in the literature $(12-17)$. Because the variable 'age less than 60 years' was not always included in the various studies looking at low-risk patients, it was decided to perform the analysis with and without that variable as part of the low-risk group, thus carrying a form of sensitivity analysis. The variables for low-risk patients included hemoglobin greater than $90 \mathrm{~g} / \mathrm{L}$, platelets greater than $50 \times 10^{9} / \mathrm{L}$, systolic blood pressure greater than $100 \mathrm{mmHg}$, pulse less than 100 beats/min, international normalized ratio less than 1.5 and no high-risk lesion on endoscopy. For a patient to be considered at high risk for the purposes of the current analysis, three variables needed to be present. These were age 60 years or older, stigmata of high-risk lesions on endoscopy and the presence of comorbidities. Other variables associated with a high-risk status were not required in the categorization but were considered to be factors reflecting increased risk. These were hemoglobin $90 \mathrm{~g} / \mathrm{L}$ or less, platelets $50 \times 10^{9} / \mathrm{L}$ or less, systolic blood pressure $100 \mathrm{mmHg}$ or less, pulse 100 beats/min or greater, and an international normalized ratio of 1.5 or greater. Low- and high-risk groups were examined for length of hospital stay, time to endoscopy, rebleeding rate, number of surgeries and mortality.

Risk stratification was also examined based on the presence of clinical and endoscopic criteria as listed in validated prognostic scales. The Blatchford prognostic scale (18), which assesses the clinical predictors of increased risk for mortality, was used for evaluating guideline 5.1. These predictors of increased risk for mortality include patients with an NVUGIB while admitted for other reasons, age older than 60 years, shock, syncope on admission, low initial hemoglobin, blood urea, melena, hematemesis, hematochezia, the need for transfusion and comorbidities including hepatic, cardiac or renal failure, or pre-existing malignancy. The Rockall risk score (19), which was used to assess guideline 5.2, and which also considers endoscopic finding sin addition to clinical predictors, has been validated in the prediction of rebleeding and death (20-22). The Rockall risk score includes age, presence of

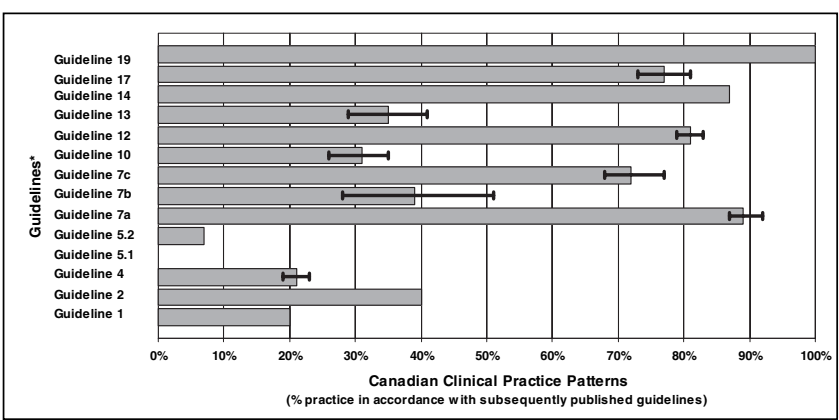

Figure 1) Summary of Canadian clinical practice patterns with respect to the nonvariceal upper gastrointestinal bleeding guidelines. *Refer to Table 1 for guideline statements. The other guidelines were not plotted because they are more descriptive and it was not possible to estimate or summarize clinical practice patterns with a single descriptive value. The 95\% CIs are only presented for the results from the Registry of patients with Upper Gastrointestinal Bleeding and Endoscopy database. The small sample size of the questionnaire limited the interpretation and clinical relevance of the CIs

shock, comorbid conditions, diagnosis and endoscopic stigmata of recent hemorrhage.

\section{Definitions}

Routine second-look endoscopy: A second endoscopy when there was no clinical rebleeding or continuous bleeding (hematemesis, melena, hematochezia, shock or drop of $20 \mathrm{~g} / \mathrm{L}$ in hemoglobin) after the first endoscopic diagnosis was made regardless of whether the patient had endoscopic treatment.

Rebleed: For the purpose of the present analysis, rebleeding included patients that had clinical rebleeding and continuous bleeding as previously defined in the original RUGBE publication (11).

\section{Presentation of results}

The results of the national sampling of practice for the management of NVUGIB are presented after each guideline. The origin of the information (questionnaire or RUGBE) is specified in parentheses.

\section{RESULTS}

Responses were obtained from all but three sites, including one community hospital, for an $83 \%$ overall response rate. In Figure 1, a summary chart depicts Canadian clinical practice patterns with respect to the NVUGIB guidelines with the CIs for the responses from the RUGBE database. Guidelines 3, 6, $8,9,11,15,16,18$ and 20 were not plotted because these guidelines are more descriptive and it was not possible to estimate or summarize clinical practice patterns with a single descriptive value.

Guideline 1: Hospitals should develop institution-specific protocols for multidisciplinary management, which should include access to an endoscopist with training in endoscopic hemostasis (questionnaire)

A question was sent to each of the 18 RUGBE sites asking if during the time when the RUGBE data were collected, their hospital had an explicit (written) protocol for the management of patients with NVUGIB. Twelve of 15 sites (80\%) where the RUGBE database was collected did not have an 
TABLE 2

Outcomes in low- and high-risk patients*

\begin{tabular}{|c|c|c|c|}
\hline Variable & $\begin{array}{l}\text { Low-risk } \\
\text { (age }<60 \text { years) }^{\dagger}\end{array}$ & $\begin{array}{l}\text { Low-risk } \\
\text { (all ages) }\end{array}$ & High-risk ${ }^{\ddagger}$ \\
\hline Patient population, $\mathrm{n}$ & 58 & 187 & 749 \\
\hline Median length of stay, days & 2.0 & 2.5 & 4.3 \\
\hline Median time to endoscopy, $\mathrm{h}$ & 15 & 15 & 11 \\
\hline Rebleed, n (\%) & $3(5)$ & $14(7)$ & $122(16)$ \\
\hline Surgery, n (\%) & $4(7)$ & $10(5)$ & $34(5)$ \\
\hline Mortality, n (\%) & $0(0)$ & $2(1)$ & $33(4)$ \\
\hline \multicolumn{4}{|l|}{ †Low-risk factors } \\
\hline \multicolumn{4}{|l|}{ Hemoglobin $>90 \mathrm{~g} / \mathrm{L}$} \\
\hline \multicolumn{4}{|l|}{ Platelets $>50 \times 10^{9} / \mathrm{L}$} \\
\hline \multicolumn{4}{|c|}{ International normalized ratio $<1.5$} \\
\hline \multicolumn{4}{|c|}{ Pulse $<100$ beats $/ \mathrm{min}$} \\
\hline \multicolumn{4}{|c|}{ Systolic blood pressure $>100 \mathrm{mmHg}$} \\
\hline \multicolumn{4}{|c|}{ No high-risk lesion on endoscopy } \\
\hline \multicolumn{4}{|c|}{ ‡High-risk factors } \\
\hline \multicolumn{4}{|c|}{ Factors required for patients to be considered high risk: } \\
\hline \multicolumn{4}{|c|}{ High-risk lesion on endoscopy } \\
\hline \multicolumn{4}{|l|}{ Age $\geq 60$ years } \\
\hline \multicolumn{4}{|l|}{ Comorbidities } \\
\hline \multicolumn{4}{|c|}{$\begin{array}{l}\text { Factors of increased risk (not required for patients to be considered } \\
\text { high risk): }\end{array}$} \\
\hline \multicolumn{4}{|l|}{ Hemoglobin $\leq 90 \mathrm{~g} / \mathrm{L}$} \\
\hline \multicolumn{4}{|l|}{ Platelets $\leq 50 \times 10^{9} / \mathrm{L}$} \\
\hline \multicolumn{4}{|c|}{ International normalized ratio $\geq 1.5$} \\
\hline \multicolumn{4}{|c|}{ Systolic blood pressure $\leq 100 \mathrm{mmHg}$} \\
\hline Pulse $\geq 100$ beats $/ \mathrm{min}$ & & & \\
\hline
\end{tabular}

${ }^{*}$ Not adjusted according to other possible confounders

explicit protocol established for NVUGIB. All sites had access to an endoscopist with training in performing endoscopic hemostasis.

Guideline 2: Support staff trained to assist in endoscopy should be available for urgent endoscopy (questionnaire) Six of 15 sites $(40 \%)$ had availability of support staff (nurses and technicians [excluding residents]) after hours for urgent endoscopy, including three community hospitals and three tertiary centres.

Guideline 3: Immediate evaluation and appropriate resuscitation are critical to proper management (RUGBE database)

The RUGBE database provided information on the initial resuscitation of the patients including vitals, IV fluids or blood products given to patients and the amount of time before these were given. Nine hundred ninety-four patients $(80 \%, 95 \%$ CI $78 \%$ to $82 \%$ ) received IV resuscitation (crystalloids or blood products including fresh frozen plasma or packed red blood cell transfusions) within $24 \mathrm{~h}$ of their initial presentation to the emergency room. The median time before receiving IV resuscitation was $2 \mathrm{~h}$ (range $12 \mathrm{~min}$ to $24 \mathrm{~h}$ ). There were 371 patients (33\% of those with available data, $95 \%$ CI $30 \%$ to $35 \%$ ) that were considered unstable, as defined by a significant change in postural vitals. Of these unstable patients, 354 (95\%, 95\% CI $93 \%$ to $97 \%$ ) received IV resuscitation within $24 \mathrm{~h}$. The median time was $1.25 \mathrm{~h}$ (range 9 min to $24 \mathrm{~h}$ ).
Guideline 4: In selected patients, the placement of a nasogastric tube can be considered because the findings may have prognostic value (RUGBE database)

In the outpatient population of the RUGBE database, 258 patients ( $21 \%, 95 \%$ CI $19 \%$ to $23 \%)$ underwent nasogastric tube insertion. Of these, 107 patients (41\%, 95\% CI 35\% to $48 \%$ ) had coffee ground emesis and 87 patients (34\%, $95 \%$ CI $28 \%$ to $40 \%$ ) had bright red blood. The remaining patients (25\%, $95 \%$ CI $19 \%$ to $30 \%)$ had either bile or none of the above findings. The majority of patients did not have a nasogastric tube inserted. In fact, there were only three RUGBE institutions $(17 \%)$ in which the majority of patients had a nasogastric tube insertion. In some cases, a nasogastric tube may not have been inserted because endoscopy was planned in the next few hours. However, even $12 \mathrm{~h}$ after their presentation and before their endoscopy, 472 patients still did not have a nasogastric tube inserted. More details regarding nasogastric tube aspirate and its prognostic implications have already formed the basis of a separate publication (23).

Guideline 5.1: Clinical (nonendoscopic) stratification of patients into low- and high-risk categories for rebleeding and mortality is important for proper management.

Available prognostic scales may be used to assist in decisionmaking (questionnaire)

During the time when the RUGBE data were collected, none of the 18 sites $(0 \%)$ routinely and explicitly used the Blatchford prognostic scale (18) to stratify patients with NVUGIB.

Guideline 5.2: Early stratification of patients into low- and high-risk categories for rebleeding and mortality, based on clinical and endoscopic criteria, is important for proper management. Available prognostic scales may be used to assist in decision making (questionnaire)

Only one of 15 sites (7\%) used the Rockall risk score (19) routinely and explicitly to stratify patients with NVUGIB.

Guideline 6: Early endoscopy (within the first 24 h) with risk classification by clinical and endoscopic criteria allows for safe and prompt discharge of patients classified as low risk; improves patient outcomes for patients classified as high risk and reduces resource use for patients classified as either low or high risk (RUGBE database)

In the outpatient population of the RUGBE database, 990 patients ( $80 \%, 95 \%$ CI $78 \%$ to $82 \%$ ) had endoscopy within $24 \mathrm{~h}$. This analysis was carried out on all patients as well as only those younger than 60 years of age.

There were 58 patients ( $95 \%$ CI $4 \%$ to $7 \%$ ) in the low-risk patient group younger than 60 years of age, representing $6 \%$ of the outpatient population (Table 2). The median length of stay was two days (range $6 \mathrm{~h}$ to 14 days). Forty-seven patients (81\%, 95\% CI 69\% to 90\%) were hospitalized for more than one day. The median time to endoscopy was $15 \mathrm{~h}$ (range $30 \mathrm{~min}$ to $62 \mathrm{~h}$ ). The rebleeding rate was 5\% (three patients, $95 \%$ CI $1 \%$ to $15 \%)$. Four patients had surgery ( $7 \%, 95 \%$ CI $2 \%$ to $17 \%$ ). There were no deaths ( $95 \%$ CI $0 \%$ to $9 \%$ ).

The second group of low-risk patients examined, which included patients without an age restriction, included 187 patients (19\%, 95\% CI 17\% to 22\%). The median length of stay was 2.5 days (range $6 \mathrm{~h}$ to 25 days). Of these, 164 patients $(88 \%, 95 \%$ CI $82 \%$ to $92 \%)$ were in hospital for 
longer than one day. The median time to endoscopy was $15 \mathrm{~h}$ (range $30 \mathrm{~min}$ to $72 \mathrm{~h}$ ). The rebleeding rate was $7 \%$ (14 patients, $95 \%$ CI $4 \%$ to $11 \%$ ). Ten patients had surgery $(5 \%, 95 \%$ CI $3 \%$ to $10 \%)$ and two patients died $(1 \%, 95 \% \mathrm{CI}$ $0 \%$ to $4 \%$ ).

Using the stratification according to the presence of at least three of the mandatory high-risk factors, 749 patients were found to belong to the high-risk group (77\% [95\% CI 75\% to $80 \%$ ] of 967 outpatients, with missing information in 273 patients). Fifty-one patients had no additional factors of increased risk, 395 patients had one factor, 215 patients had two factors, 73 patients had three factors and 15 patients had four factors. None of the patients had five additional factors of increased risk. The median length of stay for the high-risk group was 4.3 days (range $6 \mathrm{~h}$ to 29 days). Seven hundred twenty-four patients (97\%, 95\% CI 95\% to 98\%) were in hospital more than one day. The median time to endoscopy was $11 \mathrm{~h}$ (range $0 \mathrm{~min}$ to $72 \mathrm{~h}$ ). The rebleeding rate was $16 \%$ (122 patients, $95 \% \mathrm{CI}$ $13 \%$ to $19 \%), 34$ patients had surgery $(5 \%, 95 \%$ CI $3 \%$ to $6 \%)$, and 33 patients died $(4 \%, 95 \%$ CI $3 \%$ to $6 \%)$.

Guideline 7: a) A finding of low-risk endoscopic stigmata (a clean-based ulcer or a nonprotuberant pigmented dot in ulcer bed) is not an indication for endoscopic hemostatic therapy; b) A finding of a clot in an ulcer bed warrants targeted irrigation in an attempt at dislodgement, with appropriate treatment of the underlying lesion; and c) A finding of high-risk endoscopic stigmata (active bleeding of a visible vessel in an ulcer bed) is an indication for immediate endoscopic hemostatic therapy (RUGBE database)

a) In the population of patients starting to bleed in an outpatient setting of the RUGBE database, there were 729 patients (59\%, 95\% CI 56\% to $62 \%$ ) that had lowrisk endoscopic lesions excluding clots. Of these patients, 78 (11\%, 95\% CI 8\% to 13\%) had endoscopic therapy. Most of the low-risk endoscopic lesions were clean base accounting for 625 patients $(86 \%, 95 \% \mathrm{CI}$ $83 \%$ to $88 \%)$. Of these, 62 patients (10\%, 95\% CI 8\% to $12 \%$ ) received endoscopic therapy. Sixty-two patients (10\%, 95\% CI $8 \%$ to $13 \%$ ) had pigmented material, of which 15 patients $(24 \%$, $95 \%$ CI $14 \%$ to $36 \%$ ) received endoscopic treatment. Forty patients (5\%, 95\% CI 3\% to $7 \%$ ) had bleeding with no source specified and one of these patients $(2.5 \%, 95 \% \mathrm{CI} 0 \%$ to $13 \%)$ received endoscopic treatment for that indication.

b) Clots were found in 79 of 1240 patients $(6 \%, 95 \% \mathrm{CI}$ $5 \%$ to $8 \%$ ), with $31(39 \%, 95 \%$ CI $28 \%$ to $51 \%)$ receiving endoscopic therapy.

c) There were 432 patients $(35 \%, 95 \%$ CI $32 \%$ to $38 \%)$ who had high-risk endoscopic lesions. Of these, 312 patients (72\%, 95\% CI 68\% to $77 \%$ ) had endoscopic therapy. Most of the lesions were oozing, which was noted in 260 patients $(60 \%, 95 \%$ CI $56 \%$ to $65 \%)$. Of these, 182 patients $(70 \%, 95 \%$ CI $64 \%$ to $76 \%)$ received endoscopic treatment. The second most common highrisk lesion was categorized as visible vessel or visible vessel with a clot, which was found in 117 patients (27\%, 95\% CI 23\% to 31\%), 101 (86\%, 95\% CI 80\% to $93 \%$ ) of which were endoscopically treated. Of the 27 patients $(6 \%, 95 \%$ CI $4 \%$ to $9 \%)$ with a spurting ulcer, $85 \%$ (95\% CI 66\% to 96\%) of the lesions were treated endoscopically. The remaining 'other bleeding lesions' formed a very small yet heterogeneous group of patients who are not further discussed.

Guideline 8: No single solution for endoscopic injection therapy is superior to another for hemostasis (RUGBE database)

In the outpatient population of the RUGBE database, 421 patients $(34 \%$, 95\% CI $31 \%$ to $37 \%$ ) received endoscopic therapy. Of these patients, $73 \%$ (95\% CI $69 \%$ to $77 \%$ ) received injection therapy for hemostasis: 169 patients $(40 \%$, 95\% CI 36\% to 45\%) received saline, 294 (70\%, 95\% CI 66\% to $75 \%)$ received adrenaline and $17(4 \%, 95 \%$ CI $2 \%$ to $6 \%)$ received ethanolamine (some patients received more than one type of injection). Thirty-nine per cent (95\% CI 33\% to 43\%) of the patients had only injection therapy for their endoscopic treatment, adrenaline being the most common.

Guideline 9: No single method of endoscopic thermal coaptive therapy is superior to another (RUGBE database) Of the 421 patients who received endoscopic therapy, 101 (24\%, 95\% CI 20\% to 28\%) received thermal therapy only. The most common thermal therapy was the bipolar in $64 \%$ (95\% CI 55\% to 74\%). The other thermal therapies included the argon plasma coagulation in $17 \%$ (95\% CI 10\% to $24 \%$ ) and the heater probe in $7 \%$ (95\% CI $2 \%$ to $12 \%$ ).

Guideline 10: Monotherapy, with injection or thermal coagulation, is an effective endoscopic hemostatic technique for high-risk stigmata; however, the combination is superior to either treatment alone (RUGBE database)

Of the 421 patients who received endoscopic therapy, 130 (31\%, 95\% CI 26\% to 35\%) in the RUGBE outpatient population received combination therapy with injection and thermal therapies. Of the 312 patients with high-risk stigmata who received endoscopy treatment, 105 (34\%, 95\% CI 28\% to $40 \%$ ) received combination endoscopic treatment.

Guideline 11: The placement of clips is a promising endoscopic hemostatic therapy for high-risk stigmata (RUGBE database)

In the outpatient RUGBE population who had endoscopic treatment, only 15 patients (4\%, 95\% CI 2\% to 6\%) had clips placed and all of them were for high-risk stigmata.

Guideline 12: Routine second-look endoscopy is not recommended (RUGBE database).

In the outpatient population of the RUGBE database, 312 patients $(25 \%, 95 \%$ CI $23 \%$ to $27 \%$ ) had a second endoscopy. Two hundred thirty-nine patients $(77 \%, 95 \% \mathrm{CI}$ $72 \%$ to $82 \%$ ), which represents $19 \%$ (95\% CI $17 \%$ to $21 \%$ ) of the overall outpatient population, had a second endoscopy for a routine second look. The remaining group included 54 patients $(17 \%, 95 \%$ CI $13 \%$ to $21 \%)$ who had the second endoscopy for rebleeding and 19 patients $(6 \%, 95 \%$ CI 3\% to $9 \%$ ) who eventually underwent surgery. In the group that had a routine second-look endoscopy, 142 patients (59\%, 95\% CI $53 \%$ to $66 \%$ ) had high-risk lesions in their first endoscopy and 108 patients (45\%, 95\% CI 39\% to 52\%) had a biopsy to diagnose $\mathrm{H}$ pylori during their second endoscopy. 
Guideline 13: In case of rebleeding, a second attempt at endoscopic therapy is generally recommended (RUGBE database)

In the RUGBE outpatient database, 158 patients (13\%, 95\% CI $11 \%$ to $15 \%$ ) were considered to have rebled (12). Of these patients, only $54(34 \%, 95 \%$ CI $27 \%$ to $41 \%)$ had a second attempt endoscopy for rebleeding and 27 patients $(50 \%$, $95 \%$ CI $36 \%$ to $64 \%$ ) had a second endoscopic therapy at the time of the endoscopy.

Guideline 14: Surgical consultation should be sought for patients who have failed endoscopic therapy (questionnaire and RUGBE database)

As per the response to the questionnaire, 13 of 15 sites (87\%) routinely sought a surgical consultation when patients rebled after endoscopic therapy. The RUGBE database revealed that there were 67 surgeries $(5 \%, 95 \%$ CI $4 \%$ to $6 \%$ ) performed during the time the RUGBE data were collected.

Guideline 15: $\mathrm{H}_{2}$-receptor antagonists are not recommended in the management of patients with acute upper gastrointestinal bleeding (RUGBE database)

In the RUGBE outpatient population, 320 patients (26\%, 95\% CI 24\% to 29\%) received an $\mathrm{H}_{2}$-receptor antagonist, $23 \%$ being the IV and 3\% being the oral formulation. Of these 320 patients who received an $\mathrm{H}_{2}$-receptor antagonist, 70 patients (22\%, 95\% CI 17\% TO 27\%) received only the $\mathrm{H}_{2}$-receptor antagonist as their medical therapy for NVUGIB. For 98 patients (31\%, 95\% CI 25\% to $36 \%$ ), the $\mathrm{H}_{2}$-receptor antagonist was used in high-risk endoscopic lesions and for 222 patients $(69 \%, 95 \%$ CI $64 \%$ to $74 \%)$, it was used in lowrisk lesions. Twelve of 430 patients (3\%, 95\% CI 1\% to 5\%) with high-risk lesions received only $\mathrm{H}_{2}$-receptor antagonist therapy, whereas this was true for 58 of 799 patients (7\%, 95\% CI 5\% to 9\%) with low-risk lesions.

Guideline 16: Somatostatin and octreotide are not recommended in the routine management of patients with acute NVUGIB (RUGBE database)

In the outpatient population of the RUGBE database, somatostatin or octreotide was used in conjunction with other treatments in 78 patients $(6 \%, 95 \%$ CI $5 \%$ to $7 \%)$. These medications were used in 46 patients $(59 \%, 95 \%$ CI $47 \%$ to $70 \%$ ) with high-risk endoscopic lesions and 32 patients (41\%, 95\% CI 30\% to 53\%) with low-risk lesions. Of 158 patients that rebled, somatostatin and octreotide were used in 34 (22\%, 95\% CI 15\% to 28\%). Among the 67 patients who had surgery, these medications were used in nine (13\%, 95\% CI 10\% to $16 \%)$.

Guideline 17: An IV bolus followed by continuousinfusion proton pump inhibitor is effective in decreasing rebleeding in patients who have undergone successful endoscopic therapy (RUGBE database)

In the RUGBE outpatient database, 1028 patients (83\%, $95 \%$ CI $81 \%$ to $85 \%$ ) received a proton pump inhibitor (PPI). Of those receiving endoscopic treatment, 396 patients (94\%, 95\% CI 91\% to 96\%) were given a PPI. Of these patients, 297 $(75 \%, 95 \%$ CI $73 \%$ to $81 \%)$ received an IV PPI and 316 patients $(80 \%, 95 \%$ CI $76 \%$ to $84 \%)$ received an oral PPI. For 296 patients $(75 \%, 95 \%$ CI $71 \%$ to $79 \%$ ), the PPI was used to treat high-risk endoscopic lesions, and for 100 patients ( $25 \%, 95 \%$ CI $21 \%$ to $29 \%$ ), it was used to treat low-risk lesions. A more detailed analysis examining doses has previously been published (11).

Guideline 18: In patients awaiting endoscopy, empirical therapy with a high-dose PPI should be considered (questionnaire)

For this guideline, a number of questions were sent to the 18 sites. Seven of 15 sites (47\%) routinely started high-dose PPI pre-endoscopy. Of those, two sites were from community hospitals. Five of the seven sites that routinely started high-dose PPI pre-endoscopy $(71 \%)$ predominantly used IV bolus and infusion. The remainder predominantly used IV bolus only. No site used predominantly the oral double dose.

Guideline 19: Patients considered at low risk for rebleeding after endoscopy can be fed within $24 \mathrm{~h}$ (questionnaire)

All 15 sites $(100 \%)$ responded that patients with low-risk lesions on endoscopy were routinely fed within $24 \mathrm{~h}$.

Guideline 20: Patients with upper GI bleeding should be tested for $\mathrm{H}$ pylori and receive eradication therapy (RUGBE database and questionnaire)

In the RUGBE database, of the population whot presented as outpatients, 642 patients (52\%, 95\% CI 49\% to 55\%) were tested for $\mathrm{H}$ pylori while in hospital. Of these, 250 patients tested positive for $\mathrm{H}$ pylori; however, there was a significant amount of missing data (634 patients) regarding that specific variable. The most common diagnostic method used was histology in 503 patients $(79 \%, 95 \%$ CI $76 \%$ to $83 \%)$, rapid urease test in 63 patients $(10 \%, 95 \%$ CI $7 \%$ to $12 \%)$, serology in 35 patients $(5 \%, 95 \%$ CI $4 \%$ to $7 \%)$ and more than one method in the remainder. Only 87 patients (35\%, 95\% CI 29\% to 41\%) who were diagnosed with $H$ pylori were treated while in hospital. Some patients were not tested and there were a total of 133 patients who were treated for $\mathrm{H}$ pylori eradication. Of these patients, $83(62 \%, 95 \%$ CI $54 \%$ to $71 \%)$ were treated with a PPI, amoxicillin and clarithromycin, 41 patients $(31 \%$, $95 \%$ CI $23 \%$ to $39 \%$ ) with a PPI, metronidazole and clarithromycin, six patients $(5 \%, 95 \%$ CI $1 \%$ to $8 \%)$ with a PPI, amoxicillin and metronidazole and three patients (2\%, 95\% CI $0 \%$ to $6 \%$ ) with another therapy.

For this guideline, a few questions were also sent to the 18 sites. The results showed that 12 of 15 sites (80\%) were systematically testing for $\mathrm{H}$ pylori in patients with PUD while in hospital for NVUGIB. Most of the 12 sites (92\%) were using histology as the preferred method of diagnosis, while the remainder used serology $(6 \%)$ or urea breath test $(2 \%)$. Seven of these 12 sites (58\%) systematically treated patients with $H$ pylori while in hospital.

\section{DISCUSSION}

NVUGIB is common and has significant morbidity and mortality. It is surprising that with the evolving technology in managing this condition, there have been very few guidelines published. The Canadian consensus guidelines published in November 2003 (5) offer recommendations on how to optimally manage NVUGIB. The purpose of the present study was to compare and benchmark present Canadian clinical practice patterns with these guidelines at baseline, before their publication, using a national Canadian database of 18 universitybased and community institutions (11). 
The RUGBE database (11) is comparable with other previously published large databases $(1,24,25)$ with regard to patient demographics, baseline clinical predictors of mortality and rebleeding, and endoscopic findings (26-29). The clinical outcomes of rebleeding, surgery and death in the RUGBE database (5) are in keeping with the best outcomes published (26-29), especially considering the ill nature of the patient population.

\section{Initial management}

Interestingly, only three RUGBE sites (20\%) had a written explicit protocol for NVUGIB management established in hospitals. Of the three sites, one was a community hospital. In addition, only $40 \%$ of the sites had the availability of specially trained endoscopy support staff (nurses, technicians) after regular hours. Most endoscopies were performed within $24 \mathrm{~h}$ and almost all patients received early IV resuscitation. It is impossible to know why all patients did not receive early resuscitation, but the exact charting and availability of such information in view of the retrospective nature of the data collection may have influenced the results. If patients manifested symptoms or signs of hemodynamic instability, they were appropriately treated faster and received more aggressive IV resuscitation. Recently, aggressive resuscitation has been shown to improve outcomes (30). Despite a recent finding from the RUGBE study that the nasogastric aspirate provides valuable clinical information in predicting high-risk lesions (23), it was not used very often. This may have been related, at least in part, to the increased availability of early endoscopy or at least the intent to carry it out.

\section{Risk stratification}

The Blatchford prognostic scale (18) was not used routinely to stratify patients at any of the sites. Perhaps physicians can implicitly predict whether a patient has an increased risk of mortality based on prior management experience and the patient's presenting clinical condition, including comorbidities. However, a risk score calculation may be a more explicit, rapid, reproducible and accurate way to stratify patients.

In addition, only one site used regularly the Rockall risk score (19) to stratify patients based both on clinical and endoscopic information. This risk score has been validated in the literature and can accurately predict the risk of rebleeding or death (20-22). It also permits early discharge and outpatient management of patients at low risk without an increased rate of negative consequences (20-22). It is now recommended that risk stratification be performed, which represents an important new upcoming challenge in educating all sites that manage NVUGIB. This aspect of management remains the cornerstone of appropriate care and should specifically be targeted when attempting to use explicit tools. It should formally be evaluated as a component of any assessment that is part of an educational activity.

\section{Endoscopic therapy}

In the low-risk groups, most patients had endoscopy within $24 \mathrm{~h}$ but over $80 \%$ of the patients were hospitalized for more than one day. Perhaps some of these patients could have been discharged sooner, which would have reduced resource use. However, it is surprising to see that a small percentage of lowrisk patients underwent surgery, and perhaps less so that there were two mortalities in the low-risk group of patients older than 60 years of age. The high-risk group of patients had endoscopy on average approximately $4 \mathrm{~h}$ sooner than the lowrisk group, and there was a higher rate of rebleeding. The patients were in hospital for a longer period of time and there were more deaths in this group. The percentage of surgery was similar in both the low- and high-risk groups, probably in part related to low numbers. In the end, in general, physicians responded more quickly to the sicker patients, which may have improved outcomes. In RUGBE, the use of therapeutic endoscopy in patients with high-risk lesions was an independent predictor of improved outcomes (11).

In patients with low-risk lesions, $11 \%$ received endoscopic therapy, mostly for lesions that were clean-based or with pigmented spots. These lesions may not have required endoscopic hemostatic treatment, but a more rigorous assessment of appropriateness is limited in part by the retrospective nature of the study design. Certainly, the reasons for choosing endoscopic therapy in these patients is not known, but if the reason was lack of understanding of selection criteria, it is hoped that prospective dissemination of the guidelines will change practice patterns. Regarding lesions with clots, 39\% of patients had endoscopic treatment. It is, however, unclear in some as to whether the treatment involved irrigation, dislodgement of the clot and hemostatic treatment as per the current guideline recommendation. It is recognized that the decision to remove clots remains a somewhat controversial issue. Only $72 \%$ of the patients with high-risk lesions received endoscopic therapy, perhaps because of inability to perform endoscopic therapy. A full 14\% (16 patients) of those with visible vessels did not receive endoscopic treatment. The outcomes for these patients were poor, with six rebleeding, two surgeries and one death. As well, four patients (15\%) with spurting lesions did not receive endoscopic treatment. The outcomes for these patients were rebleeding in three without any surgery or death. The reasons for such conservative management are unknown, but may be multifactorial.

Injection therapy seems to be the preferred endoscopic modality ( $73 \%$ of patients), with adrenaline (diluted to $1: 10,000)$ as the most common injectate. Thermal therapy was less commonly used ( $24 \%$ of patients) with bipolar being the most popular. This may reflect technical ease, including limited en face access to the bleeding lesion that is needed for a thermal modality. The combination of both these therapies was only performed in $31 \%$ of the patients undergoing endoscopy therapy. The literature now supports combination therapy in high-risk lesions as it may reduce further bleeding, the need for surgery and mortality (31). Only $4 \%$ of patients had clip placement - an alternative that has been identified as a promising, yet not currently recommended, method of hemostasis.

Three hundred twelve patients (25\%) had a second endoscopy; in 19\% for routine second-look. This approach, although somewhat controversial, is not in keeping with current recommendations. However, additional recent data $(32,33)$ suggest that planned second-look endoscopy may be useful in the subgroup of patients with high-risk endoscopic lesions. In the RUGBE database, 59\% of the routine secondlook endoscopies were performed in patients with high-risk lesions at the initial endoscopy. Only approximately one-third of the patients who rebled received a second endoscopy and one-half of these patients had a second endoscopic therapy. This may be because in some patients, the second-look endoscopy did not identify a high-risk lesion. 


\section{Pharmacotherapy}

Although the routine use of $\mathrm{H}_{2}$-receptor antagonists are not recommended in patients with NVUGIB, $26 \%$ received $\mathrm{H}_{2}$-receptor antagonists. This may have reflected hospital policies that restricted initial IV PPI use. In 3\% of patients with high-risk lesions, an $\mathrm{H}_{2}$-receptor antagonist was the only medication used. Only a small proportion of patients $(6 \%)$ received somatostatin or octreotide, mostly in the context of rebleeding while awaiting surgery. Most patients in the RUGBE database received PPI therapy (83\%) in conjunction with endoscopic treatment. This is in keeping with current recommendations because the use of high-dose IV PPI decreases the rebleeding and mortality rate in patients with high-risk lesions $(11,34)$. However, the high percentage of PPI use was somewhat surprising due to the paucity of data for PPI efficacy at the time of the retrospective data collection. A more extensive review of pharmacological therapy is included in the original RUGBE publication (11).

\section{Management of $\mathrm{H}$ pylori}

Most sites (80\%) test PUD patients for H pylori while in hospital. Histology seems to be the most common method of diagnosis. While only about one-third of the patients found to be positive for $H$ pylori were treated while still in hospital, we cannot estimate, using the RUGBE database, the overall proportion of patients with PUD who were ultimately treated for $\mathrm{H}$ pylori, as is recommended.

Limitations of the present study include the fact that three of 18 RUGBE site representatives did not respond to the questionnaire. Also, the collaborators had an interest in this clinical area and may not be fully representative of comparable institutions elsewhere in Canada, although we specifically aimed to include a broad spectrum of institutions widely scattered geographically. As well, the questionnaire was sent in December 2003 but the questions referred to the period of time when the RUGBE data were collected, between 1999 and
2002. This may have introduced some recall bias. In addition, there were some missing data with regard to some of the RUGBE database variables.

Nonetheless, the current study puts into context a snapshot of the contemporary care of patients with NVUGIB in Canada, allows for an initial benchmarking of performance with regard to recently published international guidelines, and for future comparisons with this initial assessment. Although the outcomes appear quite favourable compared with similar published data, we can also conclude that there is a need for improved adherence to many of the published recommendations.

\section{APPENDIX}

The RUGBE (Registry on Upper Gastrointestinal Bleeding and Endoscopy) investigators include: Alan Barkun, Carlo Fallone and Gad Friedman, McGill University, Montréal, Québec; Raymond Lahaie, Georges Ghattas and Judith Dorais, Université de Montréal, Montréal, Québec; Naoki Chiba, David Armstrong and John Marshall, McMaster University, Hamilton, Ontario; Norman Marcon, University of Toronto, Toronto, Ontario and Regional Hospital, St John, New Brunswick; Franzjoseph Schweiger, Moncton Hospital, Jonathan Love, Dalhousie University, Halifax, Nova Scotia; Alan Cockeram, Saint John, Moncton, New Brunswick; Jamie Gregor and John McDonald, University of Western Ontario, London, Ontario; Rob Enns, University of British Columbia, Vancouver, British Columbia; Richard Fedorak, Bob Bailey and Connie Switzer, University of Alberta, Edmonton, Alberta.

ACKNOWLEDGEMENT: The RUGBE initiative was a collaborative effort supported by the Canadian Association of Gastroenterology and an unrestricted grant from Altana Pharma Canada. Alan N Barkun is a research scholar of the Fonds de la Recherche en Santé du Québec.

\section{REFERENCES}

1. Blatchford O, Davidson LA, Murray WR, Blatchford M, Pell J. Acute upper gastrointestinal haemorrhage in west of Scotland: Case ascertainment study. BMJ 1997;315:510-4.

2. Spiegel BM, Ofman JJ, Woods K, Vakil NB. Minimizing recurrent peptic ulcer hemorrhage after endoscopic hemostasis: The cost effectiveness of competing strategies. Am J Gastroenterol 2003;98:86-97.

3. Marshall JK, Collins SM, Gafni A. Prediction of resource utilization and case cost for acute nonvariceal upper gastrointestinal hemorrhage at a Canadian community hospital. Am J Gastroenterol 1999;94:1841-6.

4. Barkun AN, Herba K, Adam V, Kennedy W, Fallone CA, Bardou M. High-dose intravenous proton pump inhibition following endoscopic therapy in the acute management of patients with bleeding peptic ulcers in the USA and Canada: A cost-effectiveness analysis. Aliment Pharmacol Ther 2004;19:591-600.

5. Barkun A, Bardou M, Marshall JK; Nonvariceal Upper GI Bleeding Consensus Conference Group. Consensus recommendations for managing nonvariceal upper gastrointestinal bleeding. Ann Intern Med 2003;139:843-57.

6. Worrall G, Chaulk P, Freake D. The effects of clinical practice guidelines on patient outcomes in primary care: A systematic review. CMAJ 1997;156:1705-12.

7. Grimshaw JM, Russell IT. Effect of clinical guidelines on medical practice: A systematic review of rigorous evaluations. Lancet 1993;342:1317-22.

8. Weingarten S, Stone E, Hayward R, et al. The adoption of preventive care practice guidelines by primary care physicians: Do actions match intentions? J Gen Intern Med 1995;10:138-44.

9. Weingarten SR, Reidinger MS, Conner L, et al. Practice guidelines

and reminders to reduce duration of hospital stay for patients with chest pain. An interventional trial. Ann Intern Med 1994;120:257-63.

10. Oxman AD, Thomson MA, Davis DA, Haynes RB. No magic bullets: A systematic review of 102 trials of interventions to improve professional practice. CMAJ 1995;153:1423-31.

11. Barkun AN, Sabbah S, Enns R, et al; for the RUGBE investigators. The Canadian Registry on Nonvariceal Upper Gastrointestinal Bleeding and Endoscopy (RUGBE): Endoscopic hemostasis and proton pump inhibition are associated with improved outcomes in a real-life setting. Am J Gastroenterol 2004;99:1238-46.

12. Longstreth GF, Feitelberg SP. Outpatient care of selected patients with acute non-variceal upper gastrointestinal haemorrhage. Lancet 1995;345:108-11.

13. Lai KC, Hui WM, Wong BC, Ching CK, Lam SK. A retrospective and prospective study on the safety of discharging selected patients with duodenal ulcer bleeding on the same day as endoscopy. Gastrointest Endosc 1997;45:26-30.

14. Cipolletta L, Bianco MA, Rotondano G, Marmo R, Piscopo R. Outpatient management for low-risk nonvariceal upper GI bleeding A randomized controlled trial. Gastrointest Endosc 2002;55:1-5.

15. Lee JG, Turnipseed S, Romano PS, et al. Endoscopy-based triage significantly reduces hospitalization rates and costs of treating upper GI bleeding: A randomized controlled trial. Gastrointest Endosc 1999;50:755-61.

16. Cebollero-Santamaria F, Smith J, Gioe S, et al. Selective outpatient management of upper gastrointestinal bleeding in the elderly. Am J Gastroenterol 1999;94:1242-7.

17. Longstreth GF, Feitelberg SP. Successful outpatient management of acute upper gastrointestinal hemorrhage: Use of practice guidelines in a large patient series. Gastrointest Endosc 1998;47:219-22. 
18. Blatchford O, Murray WR, Blatchford M. A risk score to predict need for treatment for upper-gastrointestinal haemorrhage. Lancet 2000;356:1318-21.

19. Rockall TA, Logan RF, Devlin HB, Northfield TC. Risk assessment after acute upper gastrointestinal haemorrhage. Gut 1996;38:316-21.

20. Vreeburg EM, Terwee CB, Snel P, et al. Validation of the Rockall risk scoring system in upper gastrointestinal bleeding. Gut 1999;44:331-5.

21. Sanders DS, Carter MJ, Goodchap RJ, Cross SS, Gleeson DC, Lobo AJ. Prospective validation of the Rockall risk scoring system for upper GI hemorrhage in subgroups of patients with varices and peptic ulcers. Am J Gastroenterol 2002;97:630-5.

22. Enns R, Barkun AN, Gregor JC, Armstrong D, Levy A. Validation of Rockall scoring system for upper gastrointestinal bleeding (UGIB) in a Canadian endoscopic database (RUGBE). Gastrointest Endosc 2003;57:AB148. (Abst)

23. Aljebreen AM, Fallone CA, Barkun AN. Nasogastric aspirate predicts high-risk endoscopic lesions in patients with acute upper-GI bleeding. Gastrointest Endosc 2004;59:172-8.

24. Rockall TA, Logan RF, Devlin HB, Northfield TC. Influencing the practice and outcome in acute upper gastrointestinal haemorrhage. Steering Committee of the National Audit of Acute Upper Gastrointestinal Haemorrhage. Gut 1997;41:606-11.

25. Silverstein FE, Gilbert DA, Tedesco FJ, Buenger NK, Persing J. The national ASGE survey on upper gastrointestinal bleeding. II. Clinical prognostic factors. Gastrointest Endosc 1981;27:80-93.

26. Perng CL, Lin HJ, Chen CJ, Lee FY, Lee SD, Lee CH. Characteristics of patients with bleeding peptic ulcer requiring emergency endoscopy and aggressive treatment. Am J Gastroenterol 1994;89:1811-4.
27. Longstreth GF. Epidemiology of hospitalization for acute upper gastrointestinal hemorrhage: A population-based study. Am J Gastroenterol 1995;90:206-10.

28. Katschinski B, Logan R, Davies J, Faulkner G, Pearson J, Langman M. Prognostic factors in upper gastrointestinal bleeding. Dig Dis Sci 1994;39:706-12.

29. Cooper GS, Chak A, Way LE, Hammar PJ, Harper DL, Rosenthal GE. Early endoscopy in upper gastrointestinal hemorrhage: Associations with recurrent bleeding, surgery, and length of hospital stay. Gastrointest Endosc 1999;49:145-52.

30. Baradarian R, Ramdhaney S, Chapalamadugu R, et al. Early intensive resuscitation of patients with upper gastrointestinal bleeding decreases mortality. Am J Gastroenterol 2004;99:619-22.

31. Calvet X, Vergara M, Brullet E, Gisbert JP, Campo R. Addition of a second endoscopic treatment following epinephrine injection improves outcome in high-risk bleeding ulcers. Gastroenterology 2004;126:441-50

32. Saeed ZA, Cole RA, Ramirez FC, Schneider FE, Hepps KS, Graham DY. Endoscopic retreatment after successful initial hemostasis prevents ulcer rebleeding: A prospective reandomized trial. Endoscopy 1996;28:288-94.

33. Chiu PW, Lam CY, Lee SW, et al. Effect of scheduled second therapeutic endoscopy on peptic ulcer rebleeding: A prospective randomized trial. Gut 2003;52:1403-7.

34. Bardou M, Toubouti Y, Benhaberou-Brun D, Rahme E, Barkun AN. Meta-analysis: Proton-pump inhibition in high-risk patients with acute peptic ulcer bleeding. Aliment Pharmacol Ther 2005;21:677-86. 


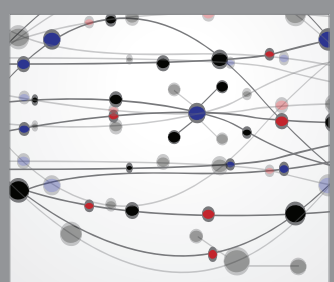

The Scientific World Journal
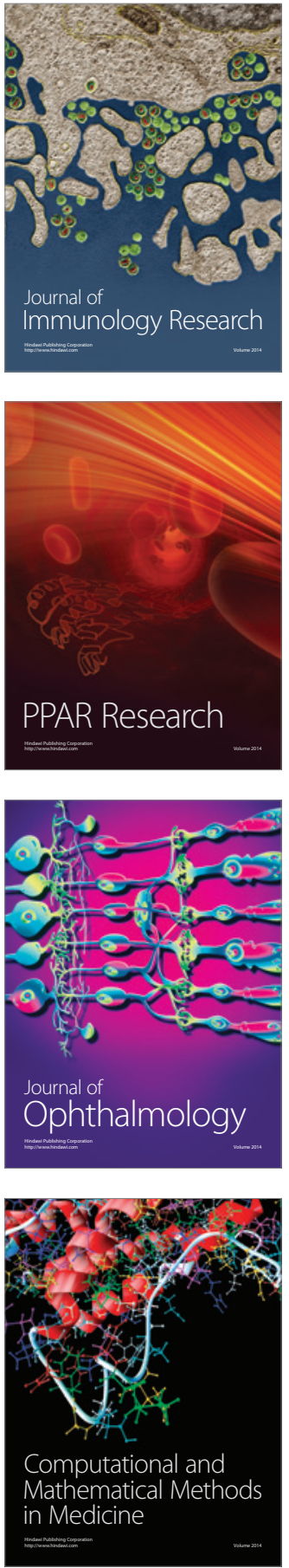

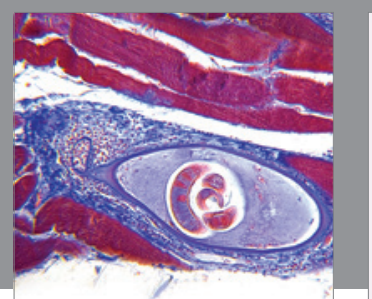

Gastroenterology Research and Practice

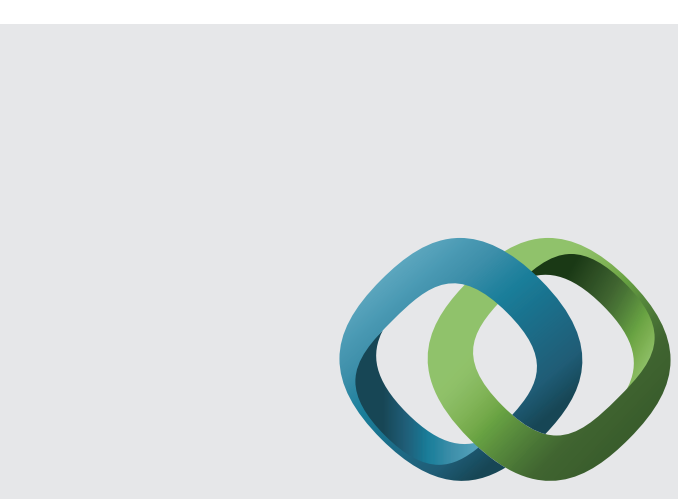

\section{Hindawi}

Submit your manuscripts at

http://www.hindawi.com
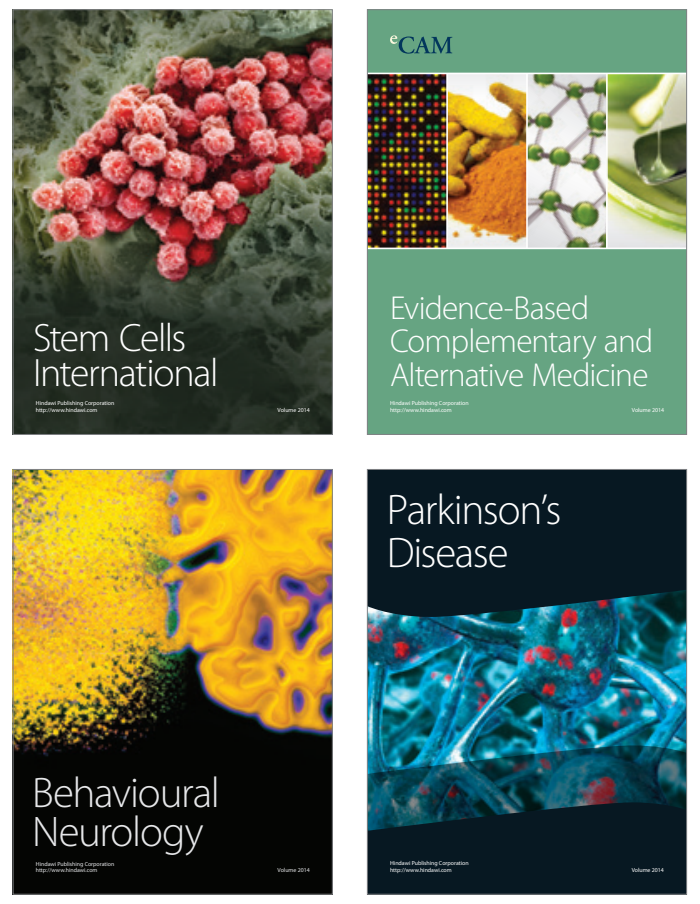
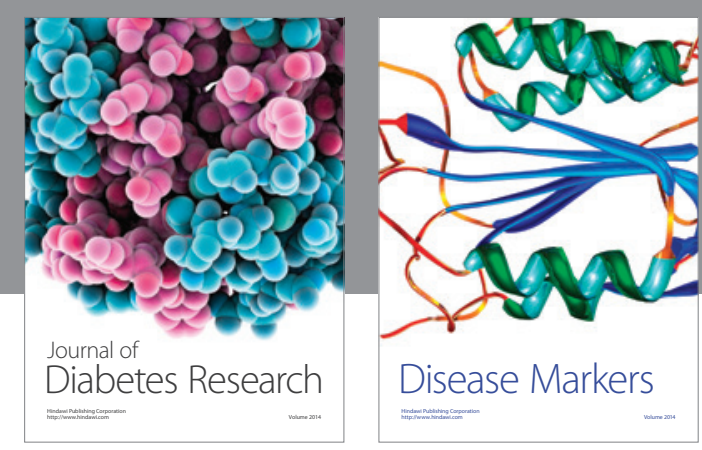

Disease Markers
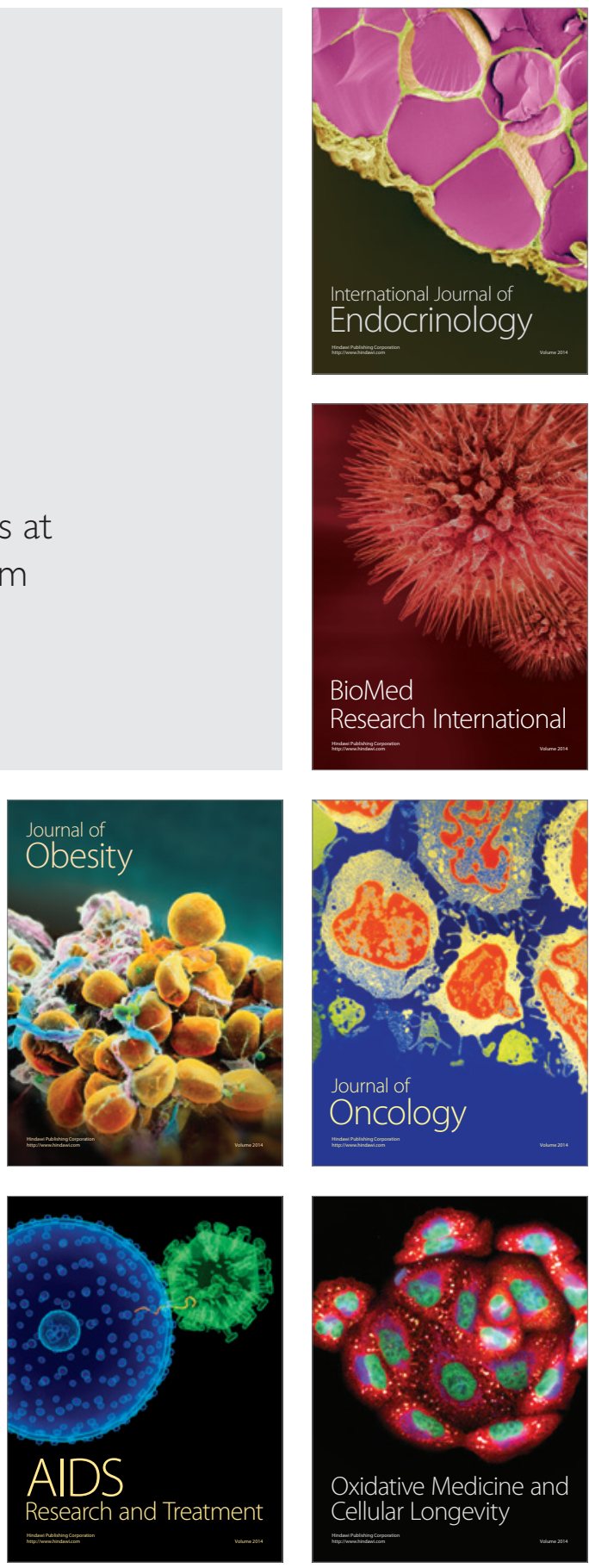